\title{
INFLUÊNCIA DOS SISTEMAS DE PASTAGEM E CONFINAMENTO NA CONTAMINAÇÃO MICROBIANA DE CARCAÇAS BOVINAS ${ }^{1}$
}

\author{
Fernanda B.B. JARDIM ${ }^{2, *}$, Edir N. da SILVA³, Mônica H. OKURA ${ }^{4}$ Márcia A. RAMOS ${ }^{5}$
}

\begin{abstract}
RESUMO
O objetivo deste trabalho foi avaliar a contaminação microbiana do couro e da superfície de carcaças bovinas, provenientes de bovinos em diferentes sistemas de engorda: extensiva em pastagem e intensiva em confinamento. Foram utilizados 40 bovinos sadios, da raça nelore, sendo metade proveniente de pastagem e a outra metade de confinamento, que foram abatidos em matadourofrigorífico sob Serviço de Inspeção Federal, localizado no Estado de Minas Gerais, Brasil. A coleta das amostras realizou-se pela técnica de esfregaço de superfície nas carcaças utilizando-se de suabe. As contagens médias (log 10 UFC/ $\left.\mathrm{cm}^{2}\right)$ de aeróbios mesófilos e anaeróbios facultativos, coliformes totais e $E$. coli foram: antes da esfola, 3,72, 1,27 e 0,86; após a esfola, 1,89, 0,40 e 0,40, e após a lavagem, 2,19,0,55 e 0,42, respectivamente, para os bovinos de pastagem; antes da esfola, 3,31, 0,65 e 0,64; após a esfola, 1,78, 0,40 e 0,40, e após a lavagem, 1,82, 0,41 e 0,40 para os bovinos de confinamento. Evidenciou-se, pela análise microbiológica, que as amostras provenientes de bovinos em pastagem apresentaram contagens médias superiores, e no caso do couro, essas diferenças foram estatisticamente significativas. Essa constatação foi confirmada pela observação visual de que os animais de confinamento apresentavam o couro "mais limpo" no momento do abate.

Palavras-chave: bovino, microrganismos, criação, abate.
\end{abstract}

\section{SUMMARY}

INFLUENCE OF PASTURE AND FEEDLOT SYSTEMS IN MICROBIAL CONTAMINATION OF BOVINE CARCASSES. The objective of this research work was to evaluate the microbial contamination of hide and surface from bovine carcasses coming from cattle under two different feeding systems: extensive, in pasture, and intensive, in feedlot. Forty healthy bovine animals from nelore breed were selected, the one-half being from pasture and the other one-half from feedlot. They were slaughtered under the Federal Inspection Service, in the slaughterhouse located in the State of Minas Gerais, Brazil. The sample collection was carried out through the surface smear technique by using swab on carcasses. The average counting $\left(\log _{10} \mathrm{CFU} / \mathrm{cm}^{2}\right)$ for mesophilic aerobes and facultative anaerobes, total coliforms and $E$. coli were, respectively: before skinning, 3.72, 1.27, and 0.86; after skinning, 1.89, 0.40 , and 0.40 ; and after washing, $2.19,0.55$, and 0.42 for the pasture cattle; before skinning, $3.31,0.65$, and 0.64 ; after skinning, 1.78 , 0.40 , and 0.40 and before washing, $1.82,0.41$, and 0.40 for the feedlot cattle. It was found through microbiological analysis that samples from cattle in pasture presented higher average counting in relation to the cattle in feedlot and, in case of the hide, these differences were statistically significant. This evidence was confirmed by the visualization of hide from animals in feedlot, which was cleaner at the moment of slaughter.

Keywords: bovine, microrganisms, feeding systems, slaughter.

\section{1 - INTRODUÇÃO}

A carne obtida de forma higiênica possui, predominantemente, uma microbiota saprófita, mas a ocorrência de bactérias patogênicas não pode ser desprezada [18]. Conforme SOFOS [25], a presença de números elevados de microorganismos nas carcaças de animais que são destinadas ao consumo humano é indesejável por que:

a) está correlacionada com deficientes práticas sanitárias;

b) pode acarretar deteriorações de produtos de forma mais rápida e intensa, assim como falhas nos tratamentos de preservação;

${ }^{1}$ Recebido para publicação em 13/10/2004. Aceito para publicação em 28/04/2006 (001415)

${ }^{2}$ Aluna de mestrado do curso de Engenharia de Alimentos da Faculdade de Engenharia de Alimentos da Unicamp, Campinas (SP)

E-mail: fernandajardim@fazu.br

${ }^{3}$ Professor titular da Faculdade de Engenharia de Alimentos da Unicamp CEP 13083-970 - Campinas (SP). E-mail: edir@fea.unicamp.br

${ }^{4}$ Professora de graduação da Faculdade de Engenharia de Alimentos (Fazu), Uberaba (MG)

${ }^{5}$ Aluna de graduação da Faculdade de Engenharia de Alimentos/FAZU, Uberaba-MG.E-mail: marciantunes@bol.com.br

*A quem a correspondência deve ser enviada c) pode aumentar a probabilidade de contaminação por patógenos como Salmonella spp. e Escherichia coli 0157:H7.

O couro, o trato gastrintestinal e o trato respiratório são os reservatórios naturais dos microorganismos nos bovinos [3, 5, 12]. O couro é a maior fonte de contaminação das carcaças, segundo SHERIDAN [23], e a presença de fezes no couro é importante fonte de patógenos em carcaças [22].

A expansão de sistemas de criação para os animais conduzidos ao abate, que demonstram limitar a presença de patógenos, é de grande importância para a saúde pública [6].

Em razão da grande aproximação dos animais durante o regime intensivo, os couros estão mais susceptíveis a acumular grandes quantidades de material fecal e, conseqüentemente, maior número de organismos fecais, em comparação com animais submetidos ao regime extensivo [26].

Entretanto, bovinos em pastagens podem estar em contato com ambientes contendo fezes, efluentes de esgoto, alimentos e água contaminados [6]. Este ambiente é susceptível à contaminação por excretas do gado e resíduos de animais selvagens e domésticos e, além disso, pessoas 
podem carrear excretas de animais de um lugar para outro, através de botas e roupas [19].

Os procedimentos de abate removem a maioria das bactérias no couro e na superfície de carcaças bovinas, incluindo alguns patógenos, mas não todos, uma vez que não há a inclusão de um tratamento letal, que assegure a eliminação de microorganismos patogênicos [21].

Os contaminantes das carcaças provêm, particularmente, do couro e do trato gastrintestinal. O controle higiênicosanitário nas operações de abate é realizado para reduzir a transferência desta contaminação para a superfície das carcaças, incluindo cuidados com as mãos, facas, serras, equipamentos e panos [15].

Os riscos higiênico-sanitários devem, preferencialmente, ser identificados com referência ao número de um organismo indicativo de contaminação fecal, como E. coli [14], através do exame de amostras de carcaças em vários estágios do processo de abate [21]. Relativamente, alta contaminação por $E$. coli em uma operação é um indicativo de Ponto Crítico de Controle - PCC, enquanto alta contaminação por aeróbios totais indica um Ponto de Controle de Qualidade - PCQ [9].

A presença de $E$. coli nas carcaças implica que outros microorganismos de origem fecal, incluindo Salmonella, podem estar presentes. A detecção de $E$. coli pode ser útil na definição dos estágios do abate responsáveis pela contaminação e disseminação bacterianas e indicação da presença de Salmonella spp. nas carcaças nessas etapas [13].

A performance de uma etapa individual para o tratamento de carcaças na operação de abate tende a ser consistente com relação às contagens de microorganismos aeróbios, coliformes e E. coli depositadas nas carcaças, permanecendo mais constantes, de acordo com a estação do ano e método de criação [16, 8].

Com objetivo de identificar pontos críticos de controle no processo de produção de carne moída, estudo foi conduzido analisando 25 carcaças bovinas pela técnica de suabe em superfície $\left(100 \mathrm{~cm}^{2}\right.$ ) após a esfola em um abatedouro, obtendo-se valores médios de 1,86 $\log 10 \mathrm{UFC} / \mathrm{cm}^{2}$ para aeróbios totais, $3,27 \log 10 \mathrm{UFC} / 2.500 \mathrm{~cm}^{2}$ para coliformes totais e $3,16 \log 10 \mathrm{UFC} / 2.500 \mathrm{~cm}^{2}$ para E. coli [7].

JERICHO, LANEY e KOZUB [17] verificaram as condições higiênicas de 120 carcaças bovinas após a lavagem e obtiveram através da técnica de excisão de um tecido $\left(25 \mathrm{~cm}^{2}\right)$ de três regióes da carcaça (alcatra, peito e sacro), contagens médias $\left(\log 10 \mathrm{UFC} / \mathrm{cm}^{2}\right)$ de 1,972 para aeróbios totais, 0,495 para coliformes totais e 0,396 para E. coli. Outro estudo avaliou as condições higiênicas de 36 carcaças bovinas após a lavagem através da técnica de suabe em superfície $\left(100 \mathrm{~cm}^{2}\right)$ e obteve contagens de aeróbios totais variando de 2,80 a 4,30 $\log 10 \mathrm{UFC} / \mathrm{cm}^{2}$ [20].

Estudo semelhante avaliando a condição de 50 carcaças bovinas em um pequeno abatedouro foi conduzido por GILL et al. [10], através da técnica da esponja $\left(100 \mathrm{~cm}^{2}\right)$, após a lavagem das carcaças bovinas. As contagens médias de aeróbios totais, coliformes e $E$. coli obtidas pelos autores foram 2,50 $\log 10 \mathrm{UFC} / \mathrm{cm}^{2}, 2,00 \log 10 \mathrm{UFC} / 100 \mathrm{~cm}^{2} \mathrm{e}$ $1,50 \log 10 \mathrm{UFC} / 100 \mathrm{~cm}^{2}$, respectivamente.

A população microbiana na superfície da carcaça bovina em diferentes estágios do abate em oito plantas foi determinada também utilizando a técnica da esponja ( 100 $\mathrm{cm}^{2}$ ) em três regiões da carcaça: flanco, peito e alcatra por BACON et al. [4]. Os autores obtiveram valores (log10 UFC/ $\mathrm{cm}^{2}$ ) variando de 6,2 a 10,5 para contagem total, 4,0 a 5,9 para coliformes totais e 3,5 a 5,5 para $E$. coli nas carcaças antes da esfola (couro), enquanto o nível de contaminação observado após a esfola estava na faixa de 4,1 a 7,1, 1,0 a 4,0 e 0,6 a 3,3, respectivamente [4].

Este trabalho teve como objetivo analisar a influência de diferentes sistemas de engorda a que bovinos foram submetidos, extensiva em pastagem e intensiva em confinamento, na contaminação do couro e superfície de carcaças bovinas em diferentes operações de abate.

\section{2 - MATERIAL E MÉTODOS}

\section{1 - Amostragem}

Foram selecionados 40 bovinos sadios da raça nelore, sendo metade sujeita ao sistema de engorda extensiva em pastagem e metade sujeita ao sistema de engorda intensiva em confinamento.

A pesquisa foi realizada em grupos de bovinos de diferentes propriedades rurais localizadas na região do Triângulo Mineiro. Foram selecionadas quatro propriedades que adotavam o sistema de engorda em confinamento a céu aberto e cinco propriedades que adotavam o sistema de engorda em pastagem. A capacidade e área média das unidades de confinamento foram, respectivamente, de 312 bovinos e $3.175 \mathrm{~m}^{2}$, representando uma relação de 10,18 $\mathrm{m}^{2}$ de unidade de área ocupada por animal, e o período médio de permanência dos animais no confinamento foi de 90 dias. A capacidade e área média das unidades de pastagem foram, respectivamente, de 270 animais e $1.350 .000 \mathrm{~m}^{2}$, representando uma relação de $5.000 \mathrm{~m}^{2}$ de unidade de produção ocupada por animal.

O gado foi abatido no período de março a agosto de 2003, sob as mesmas condições, em matadourofrigorífico sob Serviço de Inspeção Federal (SIF), com capacidade diária e velocidade de abate, em média, respectivamente de 150-250 animais e 50 animais/h. Os animais foram transportados por via rodoviária ao abatedouro por caminhões-boiadeiro e a distância média percorrida com os bovinos provenientes de pastagem foi de $40 \mathrm{~km}$, enquanto que com os bovinos de confinamento foi de $48 \mathrm{~km}$.

\section{2 - Coleta das amostras}

As amostras provenientes dos lotes de bovinos em estudo foram selecionadas de forma aleatória. Foram 
coletadas uma ou duas amostras por visita, sendo este mínimo estabelecido, baseado na limitação prática imposta pela linha de abate ao identificar e manusear os suabes. As condições ambientais médias do experimento, medidas através de termo-higrógrafo foram: temperatura de $21^{\circ} \mathrm{C}$ e $63 \%$ de umidade relativa na coleta das amostras provenientes de bovinos em pastagem; temperatura de $24^{\circ} \mathrm{C}$ e $63 \%$ de umidade relativa na coleta das amostras de bovinos em confinamento.

A coleta de amostras no couro e superfície da carcaça realizou-se em meias carcaças, conforme ABNT [2], com auxílio de suabe pela técnica de esfregaço de superfícies nas carcaças. Os suabes foram aplicados em cinco regiões da superfície das meias carcaças (Figura 1), totalizando cinco suabes aplicados em cada amostragem.

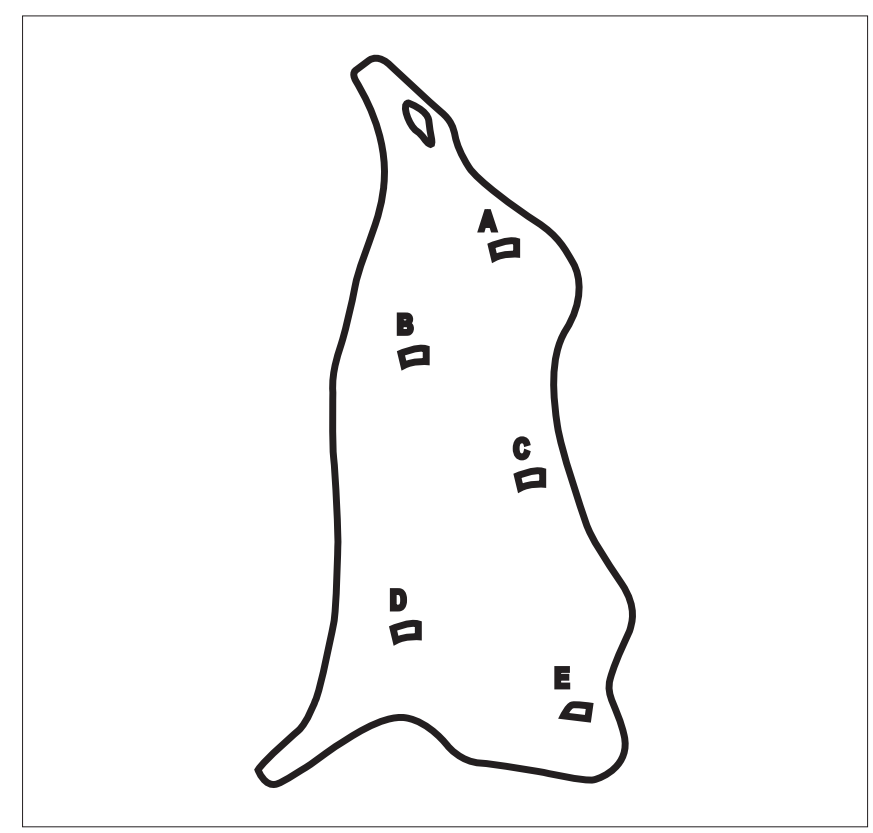

FIGURA 1 - Pontos de amostragem para coleta de amostras de meias carcaças de bovinos pela técnica do esfregaço de superfície

As regiões foram demarcadas com moldes estéreis confeccionados de aço inoxidável com área delimitada de $10 \mathrm{~cm}^{2}$ (um molde para cada ponto). Foram considerados três momentos ao longo das operações de abate para a coleta das amostras: antes da esfola (couro), após a esfola e após a lavagem (carcaça).

A forma de coleta foi padronizada, sendo cada suabe, primeiramente, imerso em solução de água peptonada esterilizada e, em seguida, aplicado em cada uma das regiões do couro e superfície das meias carcaças com pressão, numa inclinação aproximada de $45^{\circ}$, descrevendo primeiro movimentos da esquerda para a direita e depois de cima para baixo, com o cuidado de rodar continuamente o suabe, para que toda a superfície do algodão entrasse em contato com a área delimitada [24].

Efetuada a coleta, os cincos suabes foram colocados em um mesmo frasco, contendo $25 \mathrm{~mL}$ de diluente estéril 0,1\% de água peptonada e imerso em gelo para posterior exame que não excedeu $24 \mathrm{~h}$ da coleta. Todas as amostras foram obtidas pelo mesmo operador, com a utilização de luvas de látex de primeiro uso (estéreis), trocadas a cada amostragem de uma meia carcaça em determinada etapa de abate.

As amostras foram encaminhadas ao laboratório de Microbiologia de Alimentos das Faculdades Associadas de Uberaba (Fazu) para as análises. Cada frasco foi agitado manualmente (invertendo-se 25 vezes em arco de $30 \mathrm{~cm}$ ), e em seguida, utilizou-se $1 \mathrm{~mL}$ de solução para o preparo das diluições decimais pertinentes $\left(10^{-1}\right.$ a $\left.10^{-3}\right)$, estabelecidas de acordo com testes preliminares.

O volume de $1 \mathrm{~mL}$ utilizado correspondeu a uma área de $2 \mathrm{~cm}^{2}$ do couro ou superfície da carcaça amostrada. Como foram utilizados cinco suabes em cada amostragem, com aplicação em uma área total de $50 \mathrm{~cm}^{2}$ do couro ou superfície da carcaça, e os mesmos foram colocados em um mesmo frasco contendo $25 \mathrm{~mL}$ de diluente estéril, o resultado da relação área/volume $\left(50 \mathrm{~cm}^{2} / 25 \mathrm{~mL}\right)$ é equivalente a $2 \mathrm{~cm}^{2} / \mathrm{mL}$.

Para a determinação da contaminação do couro e superfície de carcaças bovinas, foram utilizadas as contagens dos grupos de microorganismos: aeróbios mesófilos e anaeróbios facultativos, coliformes totais e $E$. coli.

\section{3 - Análises microbiológicas}

Conforme descrito por SILVA, JUNQUEIRA e SILVEIRA [24], para a contagem de aeróbios mesófilos e anaeróbios facultativos, volume de $0,1 \mathrm{~mL}$ de determinada diluição foi inoculado, em duplicata, com auxílio de alça de Drigalski em placa contendo ágar padrão de contagem em placas (PCA) pelo método de plaqueamento em superfície. As colônias, que se desenvolveram após $48 \mathrm{~h}$ de incubação a $35 \pm 2^{\circ} \mathrm{C}$, foram contadas.

Conforme AOAC [1], que descreve o método 991.14 para contagem de coliformes totais e $E$. coli, volume de 1,0 $\mathrm{mL}$ de determinada diluição foi inoculado, em duplicata, na superfície de Petrifilm ${ }^{\mathrm{TM}}$ E. coli Count Plates (ECC), de acordo com as instruções do fabricante, com incubação a $35 \pm 1^{\circ} \mathrm{C}$ por $48 \pm 2 \mathrm{~h}$. Colônias vermelhas apresentando produção de gás foram contadas como coliformes totais e colônias azuis com produção de gás como E. coli. Os resultados das contagens foram expressos em log10 unidades formadoras de colônia (UFC) por unidade de área $\left(\mathrm{cm}^{2}\right)$.

\section{4 - Análise estatística}

Os resultados das contagens dos microorganismos indicadores no couro e superfície de carcaças bovinas foram submetidos ao programa estatístico modelo SAEG para Windows 8.0 de 2003, com aplicação do teste de Tukey de análise de variância e teste para comparação de médias a um nível de significância $\mathrm{p}<0,05$.

Nos resultados das contagens de aeróbios mesófilos e anaeróbios facultativos, o valor de $1,00 \log _{10} \mathrm{UFC} / \mathrm{cm}^{2}$ 
foi adotado nas análises estatísticas, quando o resultado obtido era ausência de aeróbios mesófilos e anaeróbios facultativos. Nos resultados das contagens de coliformes totais e $E$. coli, o valor de 0,40 $\log _{10} \mathrm{UFC} / \mathrm{cm}^{2}$ foi adotado nas análises estatísticas, quando o resultado obtido era ausência de coliformes totais ou ausência de $E$. coli. Estes valores foram determinados baseados no limite de detecção das análises microbiológicas.

\section{3 - RESULTADOS E DISCUSSÃO}

\section{1 - Contagens de aeróbios mesófilos e anaeróbios facultativos}

De acordo com a Tabela 1, que expressa as contagens médias de aeróbios mesófilos e anaeróbios facultativos nos grupos de bovinos em diferentes sistemas de engorda, os resultados das contagens de aeróbios mesófilos e anaeróbios facultativos nas amostras de bovinos em pastagem foram superiores em todas as operações de abate, em relação às amostras de bovinos em confinamento, com diferença entre as médias estatisticamente significantes.

TABELA 1 - Valores médios de aeróbios mesófilos e anaeróbios facultativos $\left(\log _{10} \mathrm{UFC} / \mathrm{cm}^{2}\right)$ no couro e na superfície de carcaças bovinas, de animais submetidos ao sistema de engorda extensiva em pastagem e engorda intensiva em confinamento em diferentes operações do abate

\begin{tabular}{lccc}
\hline Sistemas de engorda & \multicolumn{3}{c}{ Operações de abate } \\
\hline & Couro & \multicolumn{2}{c}{ Carcaça } \\
\hline & Antes da esfola & Após a esfola & Após a lavagem \\
\hline Pastagem & $3,72 \pm 0,71^{\mathrm{Aa}}$ & $1,89 \pm 0,55^{\mathrm{Ab}}$ & $2,19 \pm 0,74^{\mathrm{Ab}}$ \\
Confinamento & $3,31 \pm 0,45^{\mathrm{Ba}}$ & $1,78 \pm 0,41^{\mathrm{Bb}}$ & $1,82 \pm 0,37^{\mathrm{Bb}}$ \\
\hline
\end{tabular}

Nota: Médias seguidas de uma mesma letra maiúscula na coluna e minúscula na linha não diferem entre si, pelo teste de Tukey, a $5 \%$ de probabilidade. $(n=20)$

A etapa antes da esfola apresentou contagens superiores e significativamente diferentes em relação às demais operações, seguidas das etapas após a lavagem e após a esfola, sendo estas duas últimas etapas com contagens médias sem diferenças significativas.

\section{2 - Contagens de coliformes totais}

Os resultados encontrados na investigação de coliformes totais são apresentados na Tabela 2. Pode-se observar que as contagens obtidas nas amostras de bovinos em pastagem foram superiores em todas as operações de abate em relação aquelas obtidas nas amostras de bovinos em confinamento, com exceção da etapa após a esfola, onde foi detectada ausência de coliformes totais nos dois grupos de amostras. Apenas a etapa antes da esfola apresentou diferença estatisticamente significativa nessa contagem, comparando-se os dois sistemas de engorda.
TABELA 2 - Valores médios da contagem de coliformes totais $\left(\log _{10} \mathrm{UFC} / \mathrm{cm}^{2}\right)$ no couro e na superfície de carcaças bovinas, de animais submetidos ao sistema de engorda extensiva em pastagem e engorda intensiva em confinamento e diferentes operações do abate

\begin{tabular}{lccc}
\hline Sistemas de engorda & \multicolumn{3}{c}{ Operações de abate } \\
\hline & Couro & \multicolumn{2}{c}{ Carcaça } \\
\hline & Antes da esfola & Após a esfola & Após a lavagem \\
\hline Pastagem & $1,27 \pm 0,56^{\mathrm{Aa}}$ & $0,40 \pm 0,00^{\mathrm{Ab}}$ & $0,55 \pm 0,32^{\mathrm{Ab}}$ \\
Confinamento & $0,65 \pm 0,38^{\mathrm{Ba}}$ & $0,40 \pm 0,00^{\mathrm{Ab}}$ & $0,41 \pm 0,07^{\mathrm{Ab}}$
\end{tabular}

Nota: Médias seguidas de uma mesma letra maiúscula na coluna e minúscula na linha não diferem entre si, pelo teste de Tukey, a $5 \%$ de probabilidade. $(n=20)$

Pode-se observar ainda que as amostras da etapa antes da esfola em se tratando do couro proveniente de pastagem apresentou contaminação em nível superior e significativamente diferente em relação às demais operações, seguidas das etapas após a lavagem e após a esfola, ambas com contagens médias sem diferenças significativas $(p<0,05)$.

\section{3 - Contagens de E. coli}

Pelo presente estudo verificou-se que as contagens de $E$. coli nas amostras de bovinos em pastagem foram superiores em todas as operações de abate em relação às amostras de bovinos em confinamento, com exceção da etapa após a esfola, na qual foi detectada ausência de $E$. coli nos dois grupos de amostras (Tabela 3). Entretanto, não se observou diferença estatisticamente significativa $(p<0,05)$ entre os dois sistemas de engorda nas diferentes operações de abate.

Comparando-se as amostras obtidas nas diversas etapas do abate dos animais de pastagem verificou-se que as amostras de couro obtidas na etapa antes da esfola apresentaram contagens superiores e significativamente diferentes em relação às amostras das demais operações. As amostras obtidas das carcaças na etapa após a lavagem demonstraram contagens bem próximas daquelas obtidas nas amostras da etapa após a esfola, inclusive observandose a ausência de $E$. coli. O mesmo foi observado para as amostras provenientes de animais de confinamento. $\mathrm{Na}$ comparação entre animais de pastagem e de confinamento, observou-se que não houve diferença significativa entre as amostras obtidas nas diferentes etapas $(p<0,05)$.

TABELA 3 - Valores médios da contagem de $E$. coli $\left(\log _{10} \mathrm{UFC} /\right.$ $\mathrm{cm}^{2}$ ) no couro e na superfície de carcaças bovinas, de animais submetidos ao sistema de engorda extensiva em pastagem e engorda intensiva em confinamento e diferentes operações do abate

\begin{tabular}{lccc}
\hline Sistemas de engorda & \multicolumn{3}{c}{ Operações de abate } \\
\hline & Couro & \multicolumn{2}{c}{ Carcaça } \\
\hline Antes da esfola & Após a esfola & Após a lavagem \\
Pastagem & $0,86 \pm 0,52^{\mathrm{Aa}}$ & $0,40 \pm 0,00^{\mathrm{Ab}}$ & $0,42 \pm 0,11^{\mathrm{Ab}}$ \\
Confinamento & $0,64 \pm 0,36^{\mathrm{Aa}}$ & $0,40 \pm 0,00^{\mathrm{Ab}}$ & $0,40 \pm 0,00^{\mathrm{Ab}}$ \\
\hline
\end{tabular}

Nota: Médias seguidas de uma mesma letra maiúscula na coluna e minúscula na linha não diferem entre si, pelo teste de Tukey, a $5 \%$ de probabilidade. $(n=20)$ 


\section{4 - Análise das contagens dos microorganismos indicadores}

Em todas as operações de abate investigadas, os animais submetidos ao sistema de engorda intensiva em confinamento apresentaram contaminação por microorganismos indicadores em nível inferior, em comparação com os animais submetidos ao sistema de engorda extensiva em pastagem.

Na etapa antes da esfola (couro), as contagens dos microorganismos indicadores foram maiores para os dois grupos de bovinos do que nas outras etapas, indicando que o couro é uma importante fonte de contaminação, o que pode ser explicado pela possibilidade do mesmo apresentar acúmulos de fezes, microorganismos e sujeira sobre o pelame.

Esses resultados estão de acordo com aqueles apresentados em estudo de BACON et al. [4]. Entretanto, as contagens globais médias de aeróbios mesófilos e anaeróbios facultativos, coliformes totais e $E$. coli $\left(\log _{10} \mathrm{UFC} / \mathrm{cm}^{2}\right)$ antes da esfola (couro) nos dois grupos de bovinos encontradas no presente estudo foram menores do que àquelas relatadas na literatura $[4,16]$.

Na etapa após a lavagem, observou-se um aumento discreto nas contagens médias de indicadores nos dois grupos de bovinos em relação à etapa após a esfola, indicando que os processos subseqüentes à esfola podem se constituir em prováveis fontes de contaminação, como a etapa da evisceração, que é considerada um ponto crítico de controle no processo. Entretanto, esse aumento observado não apresentou diferença significativa $(\mathrm{p}<0,05)$.

As contagens de aeróbios mesófilos e anaeróbios facultativos demonstraram valores próximos aos apresentados por JERICHO, LANEY e KOZUB [17] e GILL et al. [10] e menores às encontradas por MCEVOY et al. [20]. As contagens de coliformes totais e E. coli obtidas foram também semelhantes às encontradas por JERICHO, LANEY e KOZUB [17].

As contagens de coliformes totais e E. coli após a lavagem não foram significativas nos dois grupos de bovinos em relação à etapa anterior $(\mathrm{p}<0,05)$. Supõe-se que possam ter ocorrido contaminações cruzadas, principalmente através de fezes frescas, que são fontes potenciais de contaminação, permitindo a sobrevivência destes grupos de microorganismos. Outras fontes de contaminação seriam os utensílios, equipamentos, manuseio e próprio crescimento microbiano.

Em relação aos dois grupos de amostras de bovinos, ambos obtiveram na etapa após a esfola, contagens médias menores, indicando pequeno contato entre couro/carcaça e, portanto, baixa ocorrência de contaminações cruzadas envolvendo operadores, equipamentos e utensílios.

Ainda em relação à etapa acima, a contagem média de aeróbios mesófilos e anaeróbios facultativos foi inferior à encontrada por BACON et al. [4] e semelhante à obtida por GILL, BRYANT e LANDERS [7]. Os valores médios das contagens de coliformes totais se apresentaram na faixa relatada por BACON et al. [4] e foram um pouco mais elevados aos relatados por GILL, BRYANT e LANDERS [7]. Em relação a E. coli, os valores médios da população foram inferiores aos encontrados por BACON et al. [4] e um pouco mais elevados aos encontrados por GILL, BRYANT e LANDERS [7].

Pode-se concluir que, de modo geral, os procedimentos adotados para se garantir uma esfola higiênica com um mínimo de oportunidades de contato entre couro e carcaça foram aplicados na planta de abate em estudo minimizando assim as contaminações nas superfícies das carcaças bovinas.

Os resultados globais das contagens de aeróbios mesófilos e anaeróbios facultativos, coliformes totais e E. coli apresentaram correlação, comparando-se os diferentes sistemas de engorda de bovinos. Entretanto, as diferenças observadas entre os dois grupos de bovinos foram mais relevantes e, estatisticamente significantes, nos valores médios obtidos das contagens de aeróbios mesófilos e anaeróbios facultativos.

Pela análise ou observação visual dos animais, antes do abate, verificou-se que os animais provenientes de confinamento apresentaram menos sujidades e fezes aderidas ao couro, justificado pelo manejo mais cuidadoso na fase de produção, por se tratar de um sistema de engorda oneroso e pelo fato de os animais atingirem melhor peso e conseqüentemente, melhor preço pago ao produtor.

De acordo com os resultados, pelo presente estudo, permite-se afirmar que as pastagens ofereceram um ambiente susceptível à contaminação dos bovinos, principalmente em relação ao couro, sendo eventuais fontes de contaminação as gramíneas, humanos, águas, fezes, solo e esgotos, enquanto o ambiente restrito de confinamento ofereceu menores oportunidades de contaminação dos animais.

\section{4 - CONCLUSÕES}

Considerando as avaliações dos resultados das análises microbiológicas na investigação de microorganismos indicadores no couro e superfícies de carcaças nas operações de abate e sua influência nos diferentes sistemas de engorda, pôde-se chegar às seguintes conclusões:

- $\quad$ as pastagens ofereceram um ambiente susceptível à contaminação dos bovinos, principalmente em relação ao couro, enquanto o ambiente restrito de confinamento ofereceu menores oportunidades de contaminação dos animais;

- as diferenças observadas nas contagens dos microorganismos investigados somente foram significativas quando se tratava da etapa antes da esfola;

- os níveis de coliformes totais e E. coli, tanto no couro como nas carcaças, foram muito semelhantes, podendo-se optar pela pesquisa de um ou outro indicador em investigações futuras. 


\section{5 - REFERÊNCIAS BIBLIOGRÁFICAS}

[1] AOAC. Method 991.14: Official methods of analysis of AOAC International. $17^{\text {a }}$ edição. Gaithersburg: AOAC International, 2000. p. 22-23.

[2] ASSOCIAÇÃO BRASILEIRA DE NORMAS TÉCNICAS - ABNT. Preparo da amostra para exame microbiológico. Rio de Janeiro: ABNT, 1988.

[3] AYRES, J.C. Microbiological implications in the handling, slaughter and dressing of meat animals. Advances in Food Research, v. 6, p. 109-161, 1955.

[4] BACON, R.T.; BELK, K.E.; SOFOS, J.N.; CLAYTON, R.P.; REAGAN, J.O.; SMITH, G.C. Microbial populations on animal hides and beef carcasses at different stages of slaughter in plants employing multiple-sequential interventions for decontamination. Journal of Food Protection, v. 63, n. 8, p. 1.080-1.086, 2000.

[5] FOURNAUD, J.; GRAFFINO, G.; ROSSET, R.; JACQUE, R. Contamination microbienne des carcasses a l' abattoir. Industries Alimentaires et Agricoles, v. 95, p. 273-282, 1978.

[6] GENIGEORGIS, C. The risk of transmission of zoonotic and human diseases by meat and meat products. In: SMULDERS, F.J.M. (ed.). Elimination of pathogenic organisms from meat and poultry. Amsterdam: Elsevier Science Publishers B.V., 1987, p. 111-147.

[7] GILL, C.O.; BRYANT, J.; LANDERS, C. Identification of critical control points for control of microbiological contamination in processes leading to the production of ground beef at a packing plant. Food Microbiology, v. 20, p. 641-650, 2003.

[8] GILL, C.O.; DESLANDES, B.; RAHN, K.; HOUDE, A.; BRYANT, J. Evaluation of the hygienic performances of the processes for beef carcass dressing at 10 packing plants. Journal of Applied Microbiology, v. 84, p. 1.050-1.058, 1998.

[9] GILL, C.O.; JONES, T. Assessment of the hygienic characteristics of a process for dressing pasteurizes pig carcasses. Food Microbiology, v. 14, p. 8191, 1997.

[10] GILL, C.O.; JONES, T.; BRYANT, J.; BRERETON, D.A. The microbiological conditions of the carcasses of six species after dressing at a small abattoir. Food Microbiology, v. 17, p. 233-239, 2000.

[12] GRAU, F. Fresh meats: bacterial association. Arch. Lebensmittelhyg, v. 30, p. 81, 1979.

[13] GRAU, F.H. Microbial ecology of meat and poultry. In: PEARSON, A.M.; DUTSON, T.R. (ed.). Advances in meat research: meat and poultry microbiology. Westport: AVI Publish, 1986. v. 2, cap. 1, p. 1-47.

[14] HARRIS, J.L.; STILES, M.E. Reability of Escherichia coli counts for vacuum packaged ground beef. Journal of Food Protection, v. 55, p. 266-270, 1992.

[15] INTERNATIONAL COMMISSION ON MICROBIOLOGICAL SPECIFICATIONS FOR FOOD - ICMSF. APPCC na qualidade e segurança microbiológica de alimentos: análise de perigos e pontos críticos de controle para garantir a qualidade e a segurança microbiológica de alimentos. São Paulo: Varela, 1997.

[16] JERICHO, K.W.F.; KOZUB, G.C.; BRADLEY, J.A.; GANNON, V.P.J.; GOLSTEYN-THOMAS, E.J.; GIERUS, M.; NISHIYAMA, B.J.; KING, R.K.; TANAKA, E.E.; D’SOUZA, S.; DIXION-MacDOUGALL, J.M. Microbiological verification of the control of the processes of dressing, cooling and processing of beef carcasses at a high line-speed abattoir. Food Microbiology, v. 13, p. 291-302, 1996.

[17] JERICHO, K.W.F.; LANEY, G.O.; KOZUB, G.C. Verification of the hygienic adequacy of beef carcass cooling processes by microbiological culture and the temperature-function integration technique. Journal of Food Protection, v. 61, p. 1.347-1.351, 1998.

[18] LEITÃO, M.F.F. Controle Microbiológico da Qualidade no Processamento Industrial de Bovinos. In: Ital - Centro de Tecnologia de Carne. Ciência e tecnologia da carne bovina. Campinas: Ital, 1995, cap. 13, p. 89-108.

[19] LINTON, A.H.; HINTON, M.H. Prevention of microbial contamination of red meat in the ante mortem phase: epidemiological aspects. In: SMULDERS, F.J.M. (ed.). Elimination of pathogenic organisms from meat and poultry. Amsterdam: Elsevier Science Publishers B.V., 1987, p. 9-25.

[20] MCEVOY, J.M.; SHERIDAN, J.J.; BLAIR, I.S.; MCDOWELL, D.A. Microbial contamination on beef in relation to hygiene assessment based on criteria used in EU Decision 2001/471/EC. International Journal of Food Microbiology, v. 92, p. 217-225, 2004.

[21] NATIONAL ADVISORY COMMITTEE OF MICROBIOLOGICAL CRITERIA FOR FOODS- NACMCF. Generic HACCP for raw beef. Food Microbiology, v. 10, p. 449-488, 1993.

[22] ROBERTS, T.A. Contamination of meat: the effects of slaughter practices on the bacteriology of the red meat carcass. Royal Soc. Health J., v. 100, p. 3-9, 1980.

[23] SHERIDAN, J.J. Sources of contamination during slaughter and measures for control. Journal of Food Safety, v. 18, n. 4, p. 321-339, 1998.

[24] SILVA, N. da.; JUNQUEIRA, V.C.A.; SILVEIRA, N.F.A. Manual de métodos de análise microbiológica de alimentos. São Paulo: Varela, 2001.

[25] SOFOS, J.N. Microbial growth and its control in meat, poultry and fish. In: PEARSON, A.M.; DUTSON, T.R. (eds.). Quality attributes and their measurement in meat, poultry and fish products. Glasgow: Blackie Academic and Professional, 1994, p. 359-403.

[26] VAN DONKERSGOED, J.; JERICHO, K.W.F.; GROGAN, H.; THORLAKSON, B. Preslaughter hide status of cattle and the microbiology of carcasses. Journal of Food Protection, v. 60, p. 1.502-1.508, 1997.

\section{6 - AGRADECIMENTOS}

À Capes, Faep e Fazu pelo suporte dado ao desenvolvimento desta pesquisa. 